\title{
A Better Bond: Luting Simplified
}

Raina D’Souza, Omkar Shetty, Padmapriya Puppala, Nitin Shetty

\begin{abstract}
A precise cementation is vital for a successful restoration. The adverse effects of improper cementation could result in premature occlusion, loosening of the restoration and pulpitis. The completeness of seating a restoration is influenced by vibration, venting, altering the morphology, brush technique, seating force, finger pressure and occlusal support. This article reviews and compares the different techniques for cementation and puts forth the optimal cementation procedure.
\end{abstract}

Keywords: Luting agent, Brush technique, Vibration, Finger pressure.

How to cite this article: D'Souza R, Shetty O, Puppala P, Shetty N. A Better Bond: Luting Simplified. Int J Prosthodont Restor Dent 2012;2(2):77-81.

\section{Source of support $\mathrm{Nil}$ \\ Conflict of interest: None}

\section{INTRODUCTION}

A luting agent's primary function is to fill the minute void between an indirect restoration and tooth and mechanically lock the restoration in place to prevent dislodgement during function. ${ }^{1} \mathrm{~T} 0$ achieve success meticulous attention to every detail from initial patient interview, through the active treatment phase, to a planned schedule of follow-up care is necessary. ${ }^{2}$

The overall acceptability of a cast restoration is affected by accurate seating on the tooth, minimum cement margin, good retention and restoring the function and esthetics. ${ }^{3,4}$ The more accurately the casting fits the prepared tooth the more difficult it is for cement trapped between the crown and the occlusal surface of the tooth to escape. Thus, a properly constructed fixed prosthesis may fail as a result of incomplete seating during cementation. ${ }^{5}$

J ørgensen explained that the great bulk of dental cement is at the occlusal surface during the initial phase of crown seating. A s the crown is directed to a full marginal seat, the cement must escape through the space at the marginal collar. The closer the crown approaches its ideal resting place, the smaller the space available for cement to escape. At this point the cement resists full seating of the crown because the narrow pathway for escape is closing down against the flow of noncompressible liquid. Further, the cement at the occlusal surface must travel the greatest distance and overcome frictional resistance to escape cervically. ${ }^{5}$

Improper cementation technique can also cause problems such as premature occlusion, loosening of the restoration, pulpitis and recurrent caries. ${ }^{6,7}$ The adverse effects of viscous luting cements, variations in marginal design, magnitude of seating force, cements and different seating aid materials can further complicate the crown seating during cementation. ${ }^{8}$

A precise cementation technique is vital for a successful restoration. Several procedures such as vibration, venting, altering the morphology of the restoration, painting the inner surface of the crown, magnitude of seating force have been recommended for the seating of a restoration. ${ }^{5,9}$ This article is an attempt to compare the various cementation techniques and the different ways to remove excess cement.

\section{Clinical Considerations in Cementation}

M ost practitioners are in the habit of filling the crown with cement using a cement spatula and seating it by applying continuous finger pressure and using cotton rolls as occlusal support. This method, however, does not do justice to the precise cementation that is required to ensure complete seating and even distribution of the luting agent.

The completeness of seating of a crown is influenced by internal relief, venting and vibration, the site of application of cement, the magnitude of cementation pressure, finger pressure, occlusal support and the brush technique.

\section{Internal Relief}

Internal relief is a space is created between the casting and the prepared tooth to accommodate the excess cement. Grinding the inside of the casting, internal carving of the wax pattern, etching the internal surface of the wax restoration with aqua regia and electrochemical milling of the inside of the casting are some of the methods used to provide internal relief, but these methods have been rejected as inaccurate and inconsistent. ${ }^{8} \mathrm{~A} n$ effective method of obtaining internal relief is die spacing. Paint is applied over the whole of the die except the finish line. ${ }^{5} \mathrm{D}$ ie spacer creates space for the cement film on the occlusal and axial surface of a prepared tooth. It relieves the hydraulic pressure during the initial stage of cementation and facilitates distribution of cement. A ccording to Hollenbach, a minimum of $25 \mu \mathrm{m}$ relief is necessary or the cast crown may fail to seat by approximately $100 \mu \mathrm{m} .{ }^{3,7,8,10}$ When internal relief is not provided the cement film between the casting and the prepared tooth hinders seating of cast crowns. ${ }^{5}$ 


\section{Venting of Crowns}

Perforation or venting of the occlusal surface of cast crown permits the escape of excess cement during seating. ${ }^{7,11}$ Dimashkieh and Davies found that the time of final seating of 1 minute in nonvented crowns was reduced to 15 seconds in vented crowns. ${ }^{12} \mathrm{~V}$ enting, however has some serious disadvantages: (1) A n extra visit is necessary to fill the vent hole, (2) eventual wear of the material and microleakage, (3) causes weakening of the porcelain. ${ }^{5}$

\section{Vibration}

Horizontal vibration can be achieved by gently tapping the side of a crown with a mirror handle. ${ }^{7}$ Oliveira et al found that vibration applied at the beginning of cementation improves the fit of inlays and complete crowns when they are compared to the same castings cemented without vibration. ${ }^{13} \mathrm{~K}$ oyano et al ${ }^{14}$ compared vibratory pressure and static pressure during cementation and found that static force with vibration produced thinner cement film thickness at the margins. However, because of the percussive energy in vertical vibration there is pain and fear among the patient whereas horizontal vibration is not uncomfortable to the patient. Therefore, even though the horizontal amplitude is small it is preferred to the vertical vibration. ${ }^{14}$

\section{Site of Application of the Cement}

Placing cement on the occlusal surface increases the hydrodynamic pressure within the cement. ${ }^{5}$ The amount of cement reaching the occlusal surface can be controlled by applying cement only to specific areas of the crown or preparation. I shikiriama ${ }^{15}$ found that cement painted on the inner walls of the crown promoted a better fit than when the crown was completely filled with cement. In his study an incomplete marginal seating of $54 \mu \mathrm{m}$ was found when cement was placed on the margin of the crown compared with $106 \mu \mathrm{m}$ when cement was applied on the apical 1/2 of the axial walls of the crown. When cement was applied to the apical $1 / 2$ of the axial wall of the prepared tooth, incomplete seating was $40 \mu \mathrm{m}$ and when applied to the margin of the preparation only, incomplete seating reduced to $10 \mu \mathrm{m}$.

\section{Magnitude of Cementation Pressure}

Seating force and choice of luting material strongly influences the resulting film thickness. ${ }^{8}$ D uring cementation procedures patients cannot be relied on to maintain equal force as a continuous decrease in occlusal force occurs. ${ }^{7,16}$ W ong ${ }^{9}$ has shown increased seating force results in increased pulpward pressure transmission. The delay in applying the seating force reduces the quality of cementation. A 20-second delay caused an increase in the seating gap of $0.02 \mathrm{~mm}$ and $2 \mu \mathrm{m}$ marginal gap. ${ }^{4}$

According to Jørgensen, an increase in seating force significantly reduced cement film thickness. A pparently, 5 Ib $(22 \mathrm{~N})$ of force is an inordinately light force and less than ideal for clinically seating an artificial crown. An elevation in seating force from 5 to $30 \mathrm{lb}(22-133 \mathrm{~N})$ significantly improves crown seating. It should be kept in mind that the cementation load should not exceed 5 to $7 \mathrm{~kg}$ $(50-68 \mathrm{~N})$. The optimum cementation force required to reduce the film thickness of cement was $5 \mathrm{~kg}(50 \mathrm{~N})$ for 1 minute. $^{8}$

\section{Finger Pressure}

The pressure applied during cementation depends on the dentist's finger power and obviously varies from one dentist to another. Some recent investigations have shown that the pressure applied during cementation increases the bond strength of the cement. ${ }^{17}$ White et $a^{18}$ found that cement film thickness decreased in proportion to the increase in placement force. According to Piemjai et al increased pressure during cementation may cause the cement to escape, providing for a better marginal adaptation. They suggested that a cementation pressure of $300 \mathrm{~N}$ would provide for better marginal adaptation. A moore et al compared cement pressure of five dentists by fixing a pressure tester on their finger tips and found that $60 \mathrm{~N}$ force was applied in first few seconds and 20 to $30 \mathrm{~N}$ thereafter. ${ }^{17}$

\section{Occlusal Support}

Once the crown has been inserted occlusal supports, such as E-Z bite cementation wafer, Orangewood stick, B urlew disk or M edart pressure applicator can be used to maintain the position of the crown during the setting of the cement. Cotton rolls are commonly used as occlusal support. However, Oliveira et al in his study demonstrated that cotton rolls provided poorest seating compared to B urlew disk and Orangewood blocks. Cotton roll is soft and during application of force loses its shape in order to adapt itself to the occlusal surface. The distribution of the force of closure is not homogeneously distributed and thus impairs the possibility of good seating. Sturdevant and associates indicated that Burlew disk provides more efficient cementation. They established that O rangewood blocks and Burlew disk exerted a force which is distributed mainly to the cusp tips causing irregularly distributed forces. However, the Orangewood stick may apply force to only one cusp causing the crown to rock back and forth. The M edart pressure applicator produces better adaptation. O rangew ood 
blocks and B urlew disks produced similar results but they are less efficient than M edart pressure applicator. Cotton rolls resulted in highest fit discrepancy. ${ }^{12}$

\section{The Brush Technique}

The 'brush technique' consists of the application of a small quantity of cement on the incisal edge of the preparation using the tip of sable brush no. 2 (Fig. 1). B rushed on cement produces a seating discrepancy one-third less than that resulting from filling the crown half full, and more than two-third less than that resulting from filling the crown completely. Placing smaller amount of cement in the crown will prevent a buildup of hydrostatic pressure from excess cement. $^{7}$

The interior of the crown at the margins is painted with a small quantity of cement (Fig. 2). If there are recessed features on the preparation, such as box forms or grooves apply some cement directly to the preparation with a brush (Fig. 3). Insert cement into pin holes with a small lentulo spiral or the tip of a periodontal probe and the crown is

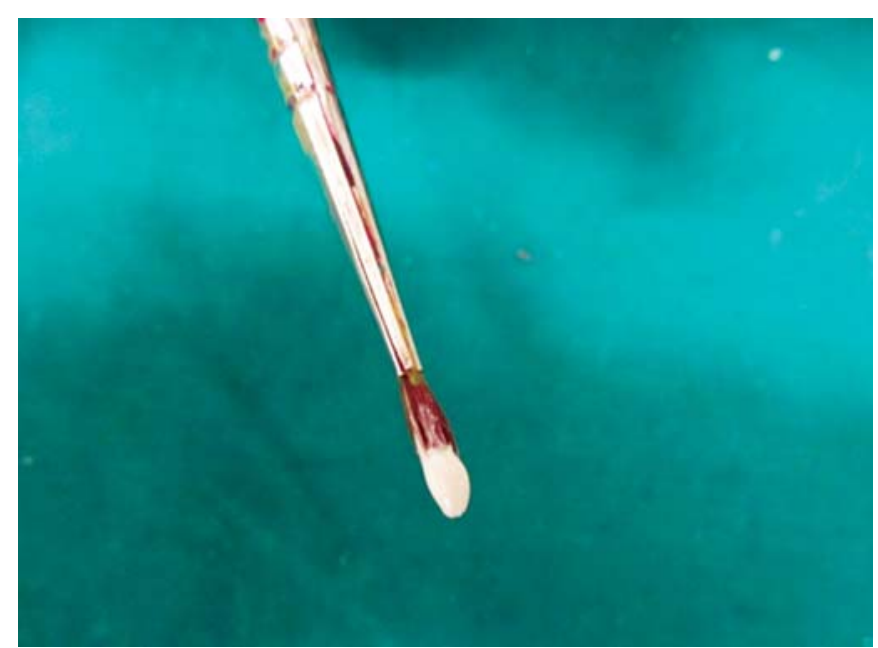

Fig. 1: Cement on a sable brush

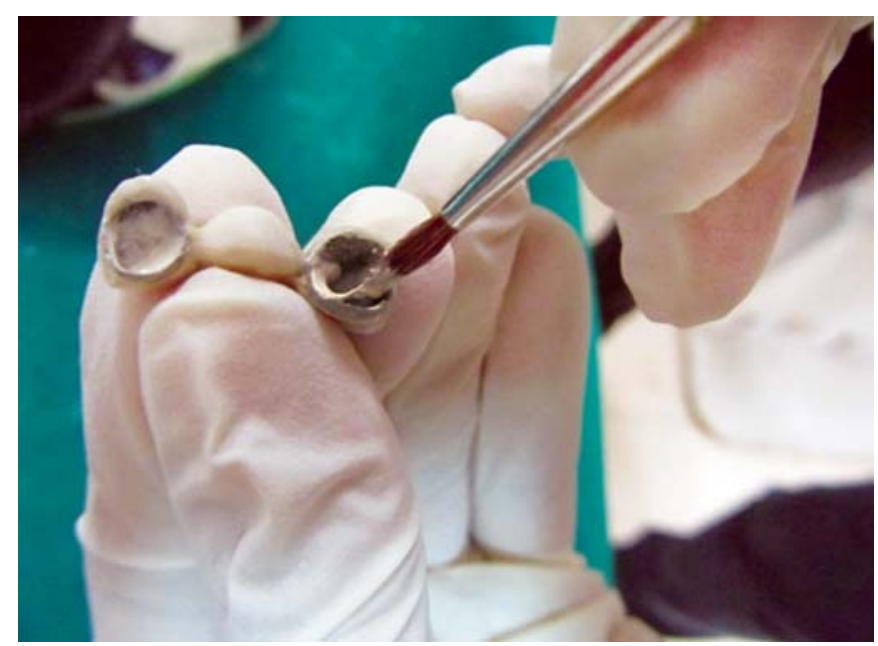

Fig. 2: Painting the interiors of the crown using a sable brush placed along its path of insertion. ${ }^{7}$ The crown is inserted slowly to about one-half the distance; it is then withdrawn by a few millimeters and reinserted to al most the full extent of its length. The process is then repeated. U se a slight up and down movement along this path to assist the layering of the cement. When the operator no longer feels any resistance, the crow $n$ is pushed to the finish line and thus to its final seating. It is necessary to avoid rotational movements to find the correct seating position as this can be damaging if porcelain margins are present.

\section{Removal of the Excess Cement}

Excess cement should not be removed while it is still soft. The excess helps protect the margins during setting. Furthermore, large masses of hardened cement will break away more easily and clearly than thin, smeared films. A common practice is to remove excess cement with a probe but the chances of removing the marginal cement and injuring the gingiva are always high. The following are a few techniques described to efficiently removeexcess cement.

\section{PKT Instrument}

Once the cement has hardened immerse the PK Thomas no. 2 waxing instrument in a silicone lubricant and enter the junctional area and remove the excess cement by following the anatomy of that area. A PK Thomas is an ideal instrument to use because it has a rounded tip and a curvature that is ideal for following the anatomic contour. It is placed against the coronal surface (Fig. 4) and inserted in the gingival sulcus in the junctional area. Apply light pressure and follow the junction to remove the cement. The purpose of this technique is to remove the cement around the contour without scratches at the crown margin. The same procedure is repeated on the lingual surface and on the interproximal surfaces (Fig. 5). $3,7,19$

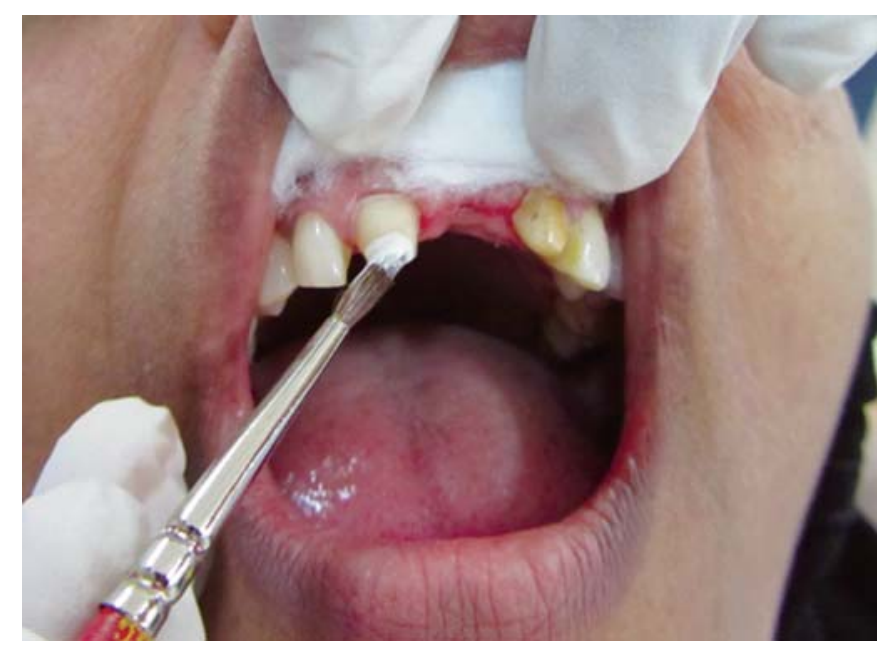

Fig. 3: Application of cement using the brush technique on the incisal edge of the tooth 


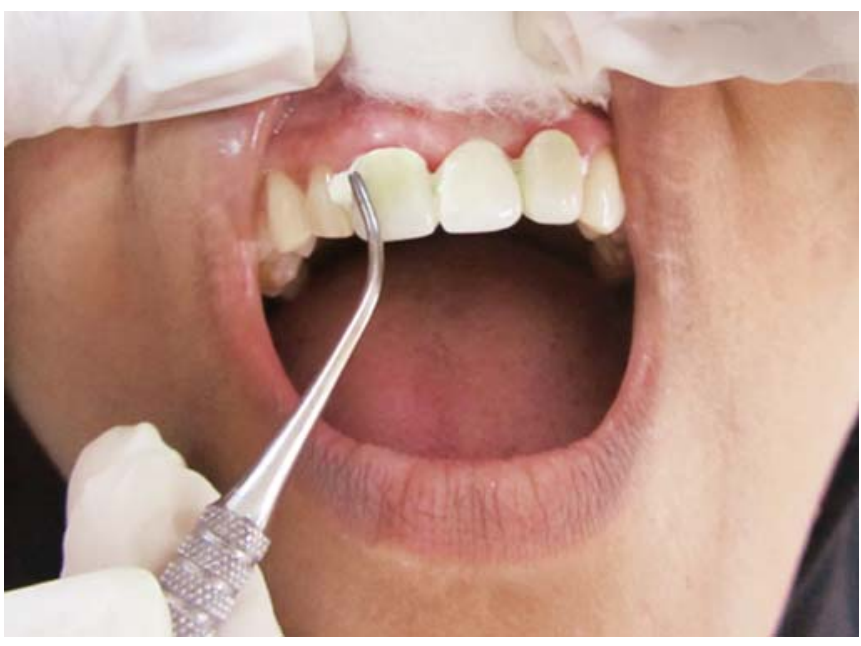

Fig. 4: PK Thomas instrument on the gingival sulcus

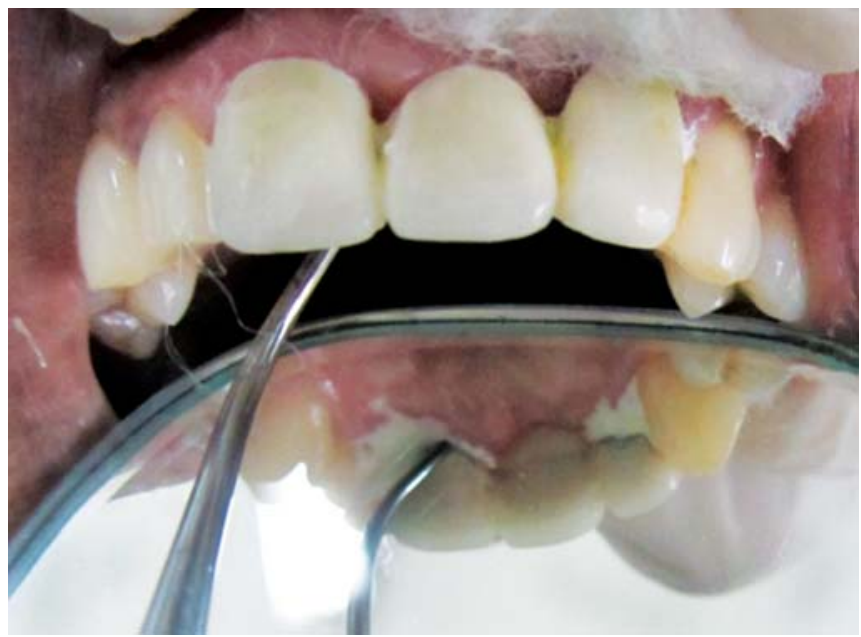

Fig. 5: PK Thomas instrument on the lingual sulcus

\section{Sable Brush}

A nother method of removing excess cement around the periphery and interproximal areas of the restoration is to use a fine sable brush. ${ }^{20}$

\section{Dental Floss}

Dental floss can be used to remove any irritating residual cementinterproximally and from the gingival sulcus. A length of dental floss for each pontic space is cut and is knotted at the center portion of each floss. Loop each piece around the prosthesis and hold the floss securely in the palm of one hand while pinching it with the fingers of that hand. In this way, the floss can act as a handle allowing the operator to have firmer and safer control over the prosthesis. A fter cementation, remove the excess cement with a PK Thomas instrument and use the pieces of floss al ready in the embrasure or pontic areas to thoroughly clean the residual cement. This step will obviate the need to thread floss through the embrasure spaces which may be blocked by the luting agent. Pull the knot in the floss back and forth under the prosthesis

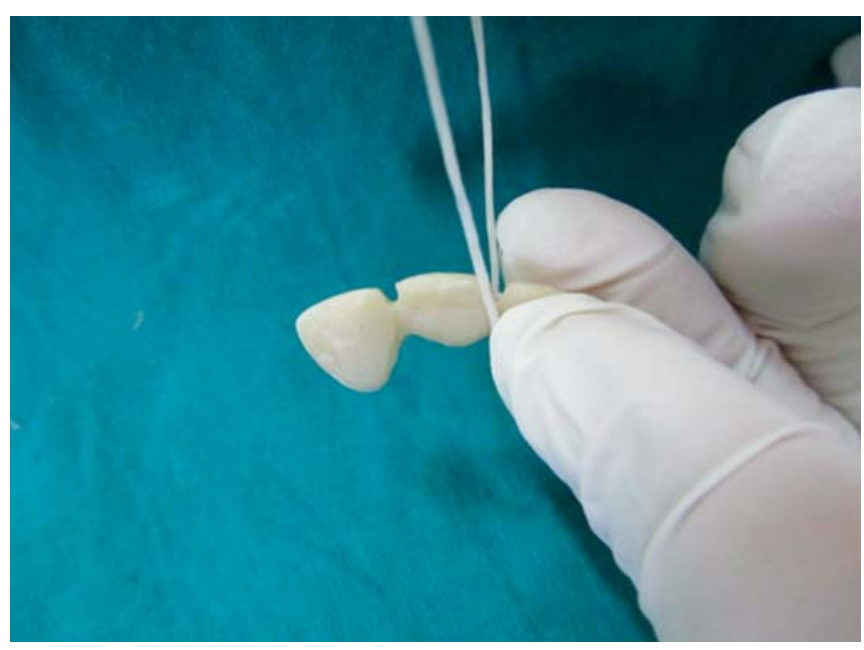

Fig. 6: Using dental floss

to provide additional cleaning force. H owever, exercise care near delicate gingival tissue (Fig. 6). ${ }^{19}$

\section{DISCUSSION}

The art of cementation is to choose cement with an inherently low film thickness and use techniques which allow it to escape while the crown is being seated. Cement flow can be hindered by preparation features which cause a buildup of hydrostatic pressure. ${ }^{21}$ The problem can be overcome by die spacing and controlled cement application or by venting of the crown. ${ }^{2}$

A nother factor which influences the complete seating of a crown and the margin adaptation is the amount of cement loaded into the crown prior to cementation. ${ }^{2}$

Venting is an effective $e^{22}$ but less popular method of reducing cement film thickness. External venting involves creating a perforation on the occlusal surface of the crown which is seated with a separate restoration after cementation. $^{2}$

The amount of force required to allow maximum seating of cast crowns has been shown to be cement-specific. Seating force must be adequate to ensure complete seating of the crow $n$ but sudden excessive force may result in elastic strain of the dentin, creating a rebound effect which results in the crow $n$ being partly dislodged when force is removed. ${ }^{23}$ $K$ arpidis and Pearson revealed that crowns seated with a force of $300 \mathrm{~N} / \mathrm{cm}^{3}$ could be removed more easily than those cemented with half the force. ${ }^{2}$ I rgensen suggested that the optimum cementation force required to reduce the film thickness of cement was $5 \mathrm{~kg}(50 \mathrm{~N})$ for 1 minute. ${ }^{8}$ However, Pilo et al stated that an increase in seating force during cementation causes an apical movement by the crown. ${ }^{5}$

Horizontal vibratory technique was found to be more effective than the static pressure. I shikiriama found that the most practical approach was to paint the casting with a thin layer of cement and vibrate it during cementation. ${ }^{1}$ 
Depending on the angulation of the tooth, pressure may then be exerted onto the crown by the dentist or by the patient biting on Cotton rolls, Orangewood blocks, Burlew disks, Medart pressure applicator and E-Z Bite wafer as this can reduce film thickness. ${ }^{13}$ However, cotton rolls resulted in highest fit discrepancy. ${ }^{2,13}$

Using the brush technique for cementation prevents the buildup of hydrostatic pressure. ${ }^{7} \mathrm{M}$ ustafa et al confirmed that a maximum pressure of $67 \mathrm{~N}$ can be applied to seat the crown. ${ }^{17}$

Literature suggests several procedures for complete seating of a crown, but no single technique gives the perfect result. The common practice is to use finger pressure and cotton rolls which often results in inaccurate cementation. 13,17

In case of conventional cements, excess cement should be left until after the cement sets. Some operators apply a smear of petroleum jelly and use a PKT instrument to remove excess cement. A common failing is for excess cement to be left especially interproximally. This can be easily removed using a dental floss. The clinician should try to incorporate any of the proven methods for a more precise cementation of the crown.

\section{CONCLUSION}

The ultimate success of a restoration depends on the accuracy of the cementation technique used. The emphasis about incomplete seating of crowns during cementation has been placed on eliminating marginal discrepancy. M ore stress should be placed on cementation technique as a means of solving the problem.

\section{REFERENCES}

1. Hill EE, Lott J. A clinically focused discussion of luting materials. A ust Dent J 2011 J un;56(Suppl 1):67-76.

2. Wassell RW, Barker D, Steele JG. Crowns and other extracoronal restorations: Try-in and cementation of crowns. B rit Dent J 2002 Jul;193(1):17-28.

3. Rosenstiel SF, Land MF, Fujimoto J. Contemporary fixed prosthodontics (4th ed). M osby 2006;909-24.

4. Kay G, Jablonski D, D ogon L. Factors affecting the seating and fit of complete crowns: A computer simulation study. J Prosthet Dent 1986 Jan;55(1):13-18.

5. Pilo R, Cardash HR, Baharav H, Helft M. Incomplete seating of cemented crowns: A literature review. J Prosthet Dent 1988;59:429-33.

6. Hoard RJ , Caputo A A, Contino RM , Koenig M E. Intracoronal pressure during crown cementation. J Prosthet Dent 1978;40(5):520-25.

7. Shillingburg H. F undamentals of fixed prosthodontics (3rd ed). Quintessence Publishing 1997;405-20.

8. Wang CJ, M illstein PL, N athanson D. Effect of cement, cement space, marginal design, seating aid materials and seating force on crown cementation. J Prosthet D ent 1992 J un;67(6):786-90.
9. Carter S, Wilson P. The effects of die spacing on post cementation crown elevation and retention. A ust Dent J 1997;42(3):192-98.

10. Sakaguchi RL, Powers J M. Craig's restorative dental materials (12th ed). Mosby 2011;479-95.

11. Hembree JH, George TA, Hembree ME. Film thickness of cements beneath complete crowns. J Prosthet Dent 1978 $M$ ay;39(5):533-35.

12. Schwartz I. A review of methods and techniques to improve the fit of cast restoration. J Prosthet D ent 1986 Sept;56(3):279-83.

13. de Freitas Oliveira J, Ishikiriama A, V ieira DF, M ondelli J. Influence of pressure and vibration during cementation. J Prosthet Dent 1979 Feb;41(2):173-77.

14. Koyano E, Iwaku M, Fusayama T. Pressuring techniques and cement thickness for cast restorations. J Prosthet Dent 1978 Nov;40(5):544-48.

15. Ishikiriam A, Oliveira J, V ieira D, M ondelli J. Influence of some factors on the fit of cemented crowns. J Prosthet Dent 1981;45:400-04.

16. W ilson P, Goodkind R, D elong R, Sakaguchi R. Deformation of crowns during cementation. J Prosthet Dent 1990 Nov;64(5):601-09.

17. Zortuk M, Bolpara P, Kilic K, Ozdemir E, A gulogli S. Effects of finger pressure applied by dentist during cementation of all ceramic crowns. Eur J Dent 20100 ct;4(4):383-88.

18. White $S N, Y u Z$, K ipnis $V$. Effect of seating force on film thickness of new adhesive luting agents. J Prosthet Dent 1992 Sept;68(3):476-81.

19. Y oungblood A. A safe and convenient technique for the cementation of fixed partial denture. JA DA 2002;133:1381.

20. Mizrachi M, Lowe R. A new and economical concept for noprep veneers. Dent Today 20110 ct;30(10):138,140-43.

21. Carter SM, Wilson PR. The effect of die spacing on crown retention. Int J Prosthodont 1996;9:21-29.

22. Kaufman EG, Colin LC, Schlagel E, Coelho DH. Factors influencing the retention of cemented gold casting: The cementing medium. J Prosthet Dent 1966;16:731-39.

23. Tjan A HL, Dunn JR, B rant BE. M arginal leakage of cast gold crowns luted with an adhesive resin cement. J Prosthet Dent 1992;67:11-15.

\section{ABOUT THE AUTHORS}

\section{Raina D'Souza (Corresponding Author)}

A ssociate Professor, Department of Prosthodontics, Dr DY Patil Dental College and Hospital, Nerul, Navi M umbai, Maharashtra-400706 India, e-mail: rainaseq@yahoo.com

\section{Omkar Shetty}

Professor and Head, Department of Prosthodontics, Dr DY Patil Dental College and Hospital, Nerul, Navi M umbai, Maharashtra, India

\section{Padmapriya Puppala}

A ssociate Professor, Department of Prosthodontics, Dr DY Patil D ental College and Hospital, Nerul, Navi M umbai, M aharashtra, India

\section{Nitin Shetty}

Senior Lecturer, Department of Prosthodontics, Dr DY Patil Dental College and Hospital, Nerul, Navi M umbai, Maharashtra, India 